\title{
COVID-19 and Digestive System Involvement: Can We Learn from the Past
}

CrossMark

\author{
Zohreh Jadali ${ }^{1, *}$
}

1. Department of Immunology, School of Public Health, Tehran University of Medical Sciences, Tehran, Iran

* Corresponding Author:

Zohreh Jadali, Ph. D

Department of Immunology, School of Public Health, Tehran University of Medical Sciences. Tehran, Iran. P.O.BOX: 6446 Tehran 14155, Iran.

Tel: + 98216462268

Fax: +98216462267

Email: zjadali@razi.tums.ac.ir or zjadali@yahoo.co.uk

Received: 25 Jun. 2020

Accepted: 10 Dec. 2020
Please cite this paper as:

Jadali Z. COVID-19 and Digestive System Involvement: Can We Learn from the Past. Middle East J Dig Dis 2021;13:166-167. doi: 10.34172/mejdd.2021.222.

Severe acute respiratory syndrome coronavirus 2 (SARS-CoV-2) which is the etiological agent of coronavirus disease 2019 (COVID-19), is a member of the large family of coronaviruses, and typically causes respiratory symptoms. In addition to primary lung infection, the virus can spread to distant vital organ such as kidneys and the digestive system which can potentially lead to organ dysfunction and various clinical presentations. ${ }^{1}$

This capacity is not a unique characteristic of SARS-CoV-2 and is observed in viruses of other families including the hepatitis $\mathrm{C}$ virus. ${ }^{2}$ Based on current clinical and epidemiological data, infection with SARS-CoV-2 can occur in the gastrointestinal (GI) tract. This is supported by evidence such as 1) detection of viral nucleic acid in stool specimens of patients infected with SARS; 2) active replication process of virus in the intestinal tissue; and 3) detection of viral nucleocapsid protein in cytoplasm of the gastric, duodenal, and rectal epithelium. ${ }^{3}$

While these observations suggest a possible relationship between SARSCoV-2 infection and GI manifestations, data paucity remains a problem. At present, it is difficult to know whether the virus can directly or indirectly invade the GI tract. In addition, the exact mechanism(s) by which disease is induced is still not clear.

Currently, there is no easy answer to address the above issues but studying literature seems to provide great help in understanding the role of cellular and molecular mechanisms that may contribute to the pathogenesis of the virus. An important point, which must be considered is the role of viruses in the induction and progression of various GI disorders and there is evidence that, viruses are one of the main etiologies of GI disturbances. ${ }^{4}$

Viruses are very diverse and cause a variety of diseases, depending on the type of virus and tissues infected. Nonetheless, significant evidence indicates that viral pathogens may use common strategies for induction and development of diseases. The three major mechanisms of viral pathogenesis are: a) the release of antigenic materials after apoptosis of virus-infected cells, b) molecular mimicry, a process by which virus infection activates $\mathrm{B}$ or $\mathrm{T}$ cells that are cross-reactive with autoantigens, c) increased production of immune-stimulatory cytokines and chemokines upon exposure to pathogens and aberrant expression 
of major histocompatibility complex class II and activation of host innate immune receptors (such as TLRs (should be spelled out) that are expressed by both epithelial and non-epithelial cells throughout the whole human GI tract). ${ }^{5}$

The above mentioned points provide valuable information about the key molecular mechanisms involved in viral spread and infection of different target organs. Although, these concerns have not been adequately investigated with respect to SARS-CoV-2 infection. At present, it can be difficult to determine which mechanism play a major role in the GI manifestations of COVID-19 infection and cause the most damage. In other words, these mechanisms do not really explain the root causes of GI disorders associated with COVID-19.

Nonetheless, careful attention to GI manifestations provide important clues that aid in early diagnosis and treatment because a significant portion of individuals with coronavirus have diarrhea, nausea, vomiting and/ or abdominal pain before respiratory symptoms. Moreover, focus on GI manifestations of COVID-19 will help prevent the spread of germs or viral particles, because some evidence suggest that fecal-oral transmission of SARS-CoV-2 can occur even after viral clearance in the respiratory tract.

\section{ETHICAL APPROVAL}

There is nothing to be declared.

\section{CONFLICT OF INTEREST}

The author declares no conflict of interest related to this work.

\section{REFERENCES}

1. Behzad S, Aghaghazvini L, Radmard AR, Gholamrezanezhad A. Extrapulmonary manifestations of COVID-19: Radiologic and clinical overview. Clin Imaging 2020;66: 35-41. doi: 10.1016/j.clinimag.2020.05.013

2. Jadali Z, Alavian SM. Autoimmune Diseases Co-Existing with Hepatitis C Virus Infection. Iran J Allergy Asthma Immunol December 2010;9: 191-206.

3. Zhang Y, Geng X, Tan Y, Li Q, Xu C, Xu J, et al. New understanding of the damage of SARS-CoV-2 infection outside the respiratory system. Biomed Pharmacother 2020;127:110195. doi: 10.1016/j.biopha.2020.110195.

4. Sanchez LC. Disorders of the gastrointestinal system. Equine Internal Medicine 2018:709-842. doi: 10.1016/ B978-0-323-44329-6.00012-7
5. Smatti MK, Cyprian FS, Nasrallah GK, Al Thani AA, Almishal RO, Yassine HM. Viruses and Autoimmunity: A Review on the Potential Interaction and Molecular Mechanisms. Viruses 2019;11:762. doi: 10.3390/ v11080762. 